\title{
Sex recognition in brown skuas: do acoustic signals matter?
}

\author{
Tim Janicke $\cdot$ Markus S. Ritz $\cdot$ Steffen Hahn • \\ Hans-Ulrich Peter
}

Received: 28 March 2007/Revised: 25 June 2007/Accepted: 27 June 2007 /Published online: 28 July 2007

(C) Dt. Ornithologen-Gesellschaft e.V. 2007

\begin{abstract}
Bird vocalisations are often essential for sex recognition, especially in species that show little morphological sex dimorphism. Brown skuas (Catharacta antarctica lonnbergi), which exhibit uniform plumage across both sexes, emit three main calls: the long call, the alarm call and the contact call. We tested the potential for sex recognition in brown skua calls of 42 genetically sexed individuals by analysing $8-12$ acoustic parameters in the temporal and frequency domains of each call type. For every call type, we failed to find sex differences in any of the acoustic parameters measured. Stepwise discriminant function analysis (DFA) revealed that sexes cannot be unambiguously classified, with increasing uncertainty of correct classification from contact calls to long calls to alarm calls. Consequently, acoustic signalling is probably not the key mechanism for sex recognition in brown skuas.
\end{abstract}

Keywords Acoustic signalling - Catharacta antarctica lonnbergi $\cdot$ Sex recognition - Vocal sexual dimorphism

Communicated by F. Bairlein.

T. Janicke $\cdot$ M. S. Ritz $\cdot$ S. Hahn $\cdot$ H.-U. Peter

Polar and Bird Ecology Group, Institute of Ecology,

Friedrich-Schiller-University,

Dornburger Strasse 159, 07743 Jena, Germany

\section{S. Hahn}

Centre for Limnology,

Netherlands Institute of Ecology (NIOO-KNAW),

P.O. Box 1299, 3600 BG Maarssen, The Netherlands

T. Janicke ( $\square)$

Zoological Institute, Evolutionary Biology,

University of Basel, Vesalgasse 1,

4051 Basel, Switzerland

e-mail: tim.janicke@unibas.ch

\section{Introduction}

In animals, sex recognition is crucial for correct pair formation and can be ensured by employing signals of various modalities (Bradbury and Vehrencamp 1998). Especially in species where sexes do not differ notably in morphology, acoustic cues become very important for sex identification and mate attraction. Accordingly, in several sexually monomorphic bird species, sex recognition is primarily based on acoustic signals (Taoka et al. 1989; Taoka and Okumura 1990; Nuechterlein and Buitron 1992; Ballintijn and ten Cate 1997). Obviously, marginal variation in vocal tract morphology leads to acoustic differences between the sexes (Suthers 2004).

So far, no data on acoustic sex differentiation and sex recognition in gulls Laridae and their close relatives, skuas Stercorariidae, have been reported. Even so, several studies on skua vocalisations assume that sexes do not differ acoustically (Pietz 1985; Charrier et al. 2001) although none of the studies rigorously tested for sex differences. We studied sex differences in vocalisations of brown skuas Catharacta antarctica lonnbergi. Brown skuas are usually monogamous and show a reversed sexual size dimorphism (Phillips et al. 2002). However, there is a wide overlap in body size and sexes differ negligibly with regard to plumage ornamentation (Olsen and Larsson 1997; Hahn and Peter 2003). Therefore, sex recognition in skuas is unlikely to be achieved by visual signals. Consequently, we hypothesised that vocalisations of brown skuas differ between sexes. To our knowledge there are no sex-specific call types in brown skuas, as reported for other seabirds, e.g. petrels Procellariidae (James 1984) and terns Sternidae (Massey 1976). Both sexes emit at least three call types depending on the behavioural context: long calls, alarm calls and contact calls (Pietz 1985; Furness 1996; Charrier 
et al. 2001). Long calls are performed to proclaim the ownership of a breeding or feeding territory and to greet the mate. Contact calls are emitted during short meetings of the pair at the nest, and alarm calls are elicited by threats, especially when intruders approach the nest. Because only the long call is likely to be involved in mate-quality recognition and mate attraction (Janicke et al. 2007), we supposed that this call type would be likely to transmit the most information about sex identity.

\section{Methods}

The study was carried out during the austral summer 2002/ 03 on Potter Peninsula, King George Island, in the Maritime Antarctic $\left(62^{\circ} 14^{\prime} \mathrm{S} 58^{\circ} 39^{\prime} \mathrm{W}\right)$. During the study season, the brown skua population on Potter Peninsula comprised 29 breeding pairs. Birds were captured by noosing their legs to allow for sex determination and individual marking by plastic bands. Birds were sexed on the basis of DNA from 50- $\mu$ l blood samples by amplifying the W-chromosome-linked CHD gene (Fridolfsson and Ellegren 1999).

Long calls, alarm calls and contact calls of brown skuas were recorded using a Sony MZ-N707 recorder and a Sennheiser K6/M66 directional microphone. Recordings were digitised at a sample rate of $22,050 \mathrm{~Hz}$ (16-bit resolution, mono) using Cool Edit Pro 2.0 from Syntrillium Software (now Adobe, San Jose, CA, USA; http:// www.adobe.com). Sound analysis was carried out with Avisoft SAS-Lab Pro 4.36 (R. Specht, Berlin, Germany). Background noise was reduced by applying the IIR highpass filter in Avisoft SAS-Lab Pro (corner frequency: $0.3 \mathrm{kHz}$ ) prior to the analysis. We analysed acoustic parameters in both the temporal domain and the frequency domain. Measurement of long calls, alarm calls and contact calls included 12, 8 and 8 acoustic parameters, respectively. In the temporal domain we measured note duration (duration of a single call note in seconds) and distance to maximum amplitude (distance from start to the location of the maximum amplitude within a note in seconds) for all call types. Because long calls represent a sequence of several single notes, the additional measurement for this call type included call composition (number of notes of an entire call), total duration (duration of an entire long call in seconds), note repetition rate (number of notes per time in notes/s), and peak performance (proportion of time during which the sound amplitude exceeds $20 \%$ of the maximum value for the whole long call, in percent). In the frequency domain of all call types, we examined peak amplitude (amplitude at the peak frequency in $\mathrm{dB}$ ), peak frequency (frequency of the maximum amplitude in $\mathrm{Hz}$ ), mean frequency (50\% quartile of the spectrum in $\mathrm{Hz}$ ), maximum frequency and minimum frequency (the frequency at which the amplitude initially rises above or drops below a threshold of $-20 \mathrm{~dB}$ in $\mathrm{Hz}$, respectively), and frequency bandwidth (the difference between the maximum and minimum frequency in $\mathrm{Hz}$ ). Long call measurements in the frequency domain were restricted to the central note of the entire long call because fully developed long calls exhibit a crescendo-decrescendo pattern (Pietz 1985).

In total, we analysed 291 long calls (121 calls of 20 males and 170 calls of 22 females), 4,504 alarm calls (2,844 calls of 20 males and 1,660 calls of 19 females) and 431 contact calls ( 213 calls of 10 males and 218 calls of 13 females). The statistical comparison of male and female vocalisations was performed by applying the linear mixedeffects models in R v.2.3.1 (R Development Core Team, R Foundation for Statistical Computing, Vienna, Austria; http://www.r-project.org/foundation/). In order to classify calls according to sex, we conducted stepwise discriminant function analyses (DFA) using the statistical software package SPSS for Windows 13.0 (SPSS Inc., Chicago, IL, USA; http://www.spss.com/). All of the variables were distributed normally (Kolmogorov-Smirnov, $p>0.05$ ), and thus parametric tests were applied. All of the tests were two-tailed, and means are given in $\pm \mathrm{SD}$.

\section{Results}

Descriptive statistics for the acoustic parameters measured for both brown skua sexes are given in Table 1. Considering all call types, vocalisations of males and females overlapped widely in all acoustic parameters measured, and no significant differences were found for any single parameter (Table 1). For long calls, stepwise DFA revealed that a combination of four of the 12 measured parameters contributed to sex discrimination: namely peak performance, note duration, peak amplitude and peak frequency, in the order in which they were included in the analysis (Wilks $\lambda=0.874$ ). However, the frequency distribution of the first discriminant score did not show a bimodal distribution but instead a wide overlap comprising $95.0 \%$ of all long calls analysed (Fig. 1a). Consequently, DFA using these four acoustic parameters classified only $63.5 \%$ of the long calls correctly to sex (the expected rate of correct classification based on chance is $50 \%$ ). In alarm calls, six of the eight measured acoustic parameters entered the DFA in the following order: mean frequency, distance to maximum amplitude, peak frequency, frequency bandwidth, peak amplitude and maximum frequency (Wilks $\lambda=0.965$ ). The first discriminant scores of both sexes overlap in $99.7 \%$ of the cases (Fig. 1b), and the DFA assigned only $60.0 \%$ correctly to sex. Stepwise DFA of contact calls included three of eight acoustic parameters in 
Table 1 Mean statistics for the acoustic parameters measured for both brown skua sexes, and the results of a sex comparison performed using linear mixed-effects models

\begin{tabular}{|c|c|c|c|c|c|}
\hline \multirow[t]{2}{*}{ Acoustic parameter } & \multicolumn{2}{|l|}{ Mean \pm SD } & \multicolumn{3}{|c|}{ Linear mixed-effects model } \\
\hline & Males & Females & $d f$ & $t$-value & $p$-value \\
\hline \multicolumn{6}{|l|}{ Long calls } \\
\hline Call composition (notes) & $9.88 \pm 2.27$ & $10.08 \pm 3.21$ & 38,221 & 0.43 & 0.673 \\
\hline Total duration (s) & $4.01 \pm 1.06$ & $4.21 \pm 1.49$ & 38,221 & -0.24 & 0.812 \\
\hline Note duration (s) & $0.19 \pm 0.03$ & $0.19 \pm 0.03$ & 40,249 & -0.76 & 0.449 \\
\hline Note repetition rate (notes/s) & $2.38 \pm 0.30$ & $2.30 \pm 0.17$ & 38,221 & 1.20 & 0.236 \\
\hline Peak performance $(\%)$ & $39.84 \pm 4.60$ & $36.84 \pm 6.38$ & 38,221 & 1.88 & 0.068 \\
\hline Distance to maximum amplitude (s) & $0.04 \pm 0.03$ & $0.04 \pm 0.03$ & 40,249 & 1.28 & 0.208 \\
\hline Peak amplitude $(\mathrm{dB})$ & $-23.00 \pm 6.06$ & $-21.68 \pm 6.36$ & 40,249 & -0.47 & 0.641 \\
\hline Peak frequency $(\mathrm{Hz})$ & $2224.86 \pm 516.15$ & $2025.82 \pm 568.50$ & 40,249 & 1.69 & 0.098 \\
\hline Mean frequency $(\mathrm{Hz})$ & $2610.93 \pm 242.56$ & $2563.59 \pm 312.41$ & 40,249 & 0.45 & 0.655 \\
\hline Minimum frequency $(\mathrm{Hz})$ & $901.44 \pm 296.63$ & $848.11 \pm 307.50$ & 40,249 & 1.24 & 0.221 \\
\hline Maximum frequency $(\mathrm{Hz})$ & $5185.56 \pm 932.41$ & $5047.98 \pm 1071.77$ & 40,249 & 0.67 & 0.508 \\
\hline Frequency bandwidth $(\mathrm{Hz})$ & $4154.64 \pm 1426.86$ & $4380.94 \pm 1366.03$ & 40,249 & 0.05 & 0.958 \\
\hline \multicolumn{6}{|l|}{ Alarm calls } \\
\hline Duration (s) & $0.59 \pm 0.13$ & $0.60 \pm 0.11$ & 37,4465 & -1.00 & 0.322 \\
\hline Distance to maximum amplitude (s) & $0.08 \pm 0.09$ & $0.10 \pm 0.10$ & 37,4465 & -0.34 & 0.722 \\
\hline Peak amplitude $(\mathrm{dB})$ & $-21.96 \pm 4.65$ & $-21.27 \pm 4.30$ & 37,4465 & 0.37 & 0.713 \\
\hline Peak frequency $(\mathrm{Hz})$ & $1313.36 \pm 253.84$ & $1259.85 \pm 216.55$ & 37,4465 & 1.78 & 0.083 \\
\hline Mean frequency $(\mathrm{Hz})$ & $1629.23 \pm 196.49$ & $1572.78 \pm 212.65$ & 37,4465 & 0.98 & 0.335 \\
\hline Minimum frequency $(\mathrm{Hz})$ & $637.51 \pm 237.00$ & $639.91 \pm 184.43$ & 37,4465 & 0.91 & 0.369 \\
\hline Maximum frequency $(\mathrm{Hz})$ & $3163.57 \pm 1092.00$ & $3029.23 \pm 1015.03$ & 37,4465 & 0.07 & 0.946 \\
\hline Frequency bandwidth $(\mathrm{Hz})$ & $2521.35 \pm 1210.40$ & $2385.27 \pm 1096.29$ & 37,4465 & -0.19 & 0.849 \\
\hline \multicolumn{6}{|l|}{ Contact calls } \\
\hline Duration (s) & $0.10 \pm 0.03$ & $0.12 \pm 0.05$ & 20,401 & -1.28 & 0.216 \\
\hline Distance to maximum amplitude (s) & $0.04 \pm 0.02$ & $0.04 \pm 0.02$ & 20,401 & 0.99 & 0.335 \\
\hline Peak amplitude $(\mathrm{dB})$ & $-21.43 \pm 3.88$ & $-19.45 \pm 3.24$ & 20,401 & -1.46 & 0.159 \\
\hline Peak frequency $(\mathrm{Hz})$ & $1263.62 \pm 382.99$ & $1255.78 \pm 225.04$ & 20,401 & 0.42 & 0.679 \\
\hline Mean frequency $(\mathrm{Hz})$ & $1673.28 \pm 252.54$ & $1669.13 \pm 244.65$ & 20,401 & 0.84 & 0.412 \\
\hline Minimum frequency $(\mathrm{Hz})$ & $475.95 \pm 191.38$ & $401.31 \pm 102.86$ & 20,401 & 0.08 & 0.933 \\
\hline Maximum frequency $(\mathrm{Hz})$ & $3437.72 \pm 940.84$ & $3443.20 \pm 947.95$ & 20,401 & -0.04 & 0.964 \\
\hline Frequency bandwidth $(\mathrm{Hz})$ & $2957.00 \pm 956.96$ & $3038.59 \pm 971.61$ & 20,401 & -0.13 & 0.898 \\
\hline
\end{tabular}

Analysis included 291 long calls, 4,504 alarm calls and 431 contact calls of 42, 39 and 23 individuals, respectively

the following order: peak amplitude, minimum frequency and note duration (Wilks $\lambda=0.753$ ). The distribution of the first discriminant scores overlapped in $94.0 \%$ of cases (Fig. 1c), and $73.0 \%$ of all contact calls could be assigned accurately to sex by the DFA.

\section{Discussion}

Our results demonstrate that the three main calls in the brown skua's vocal repertoire do not differ between males and females, and that sexes cannot be assigned correctly using acoustic cues. Neither long calls, alarm calls nor contact calls carry significant information about sex iden- tity. This suggests that sex recognition in brown skuas is not achieved by acoustic signalling. With respect to call type, the probability of correct sex classification ranged from 60 to $73 \%$, which is very low compared to an expected classification by chance of 50\%. By contrast, in sexually monomorphic collared doves Streptopelia decaocto, one acoustic parameter alone is sufficient to correctly classify all males and females (Ballintijn and ten Cate 1997). Similarly, in Yelkouan shearwaters Puffinus yelkouan, male and female vocalisations do not overlap in two acoustic parameters (Bourgeois et al. 2007).

The variation in sexual dimorphism across species is traditionally attributed to differences in social mating systems (Owens and Hartley 1998; Dunn et al. 2001). In 

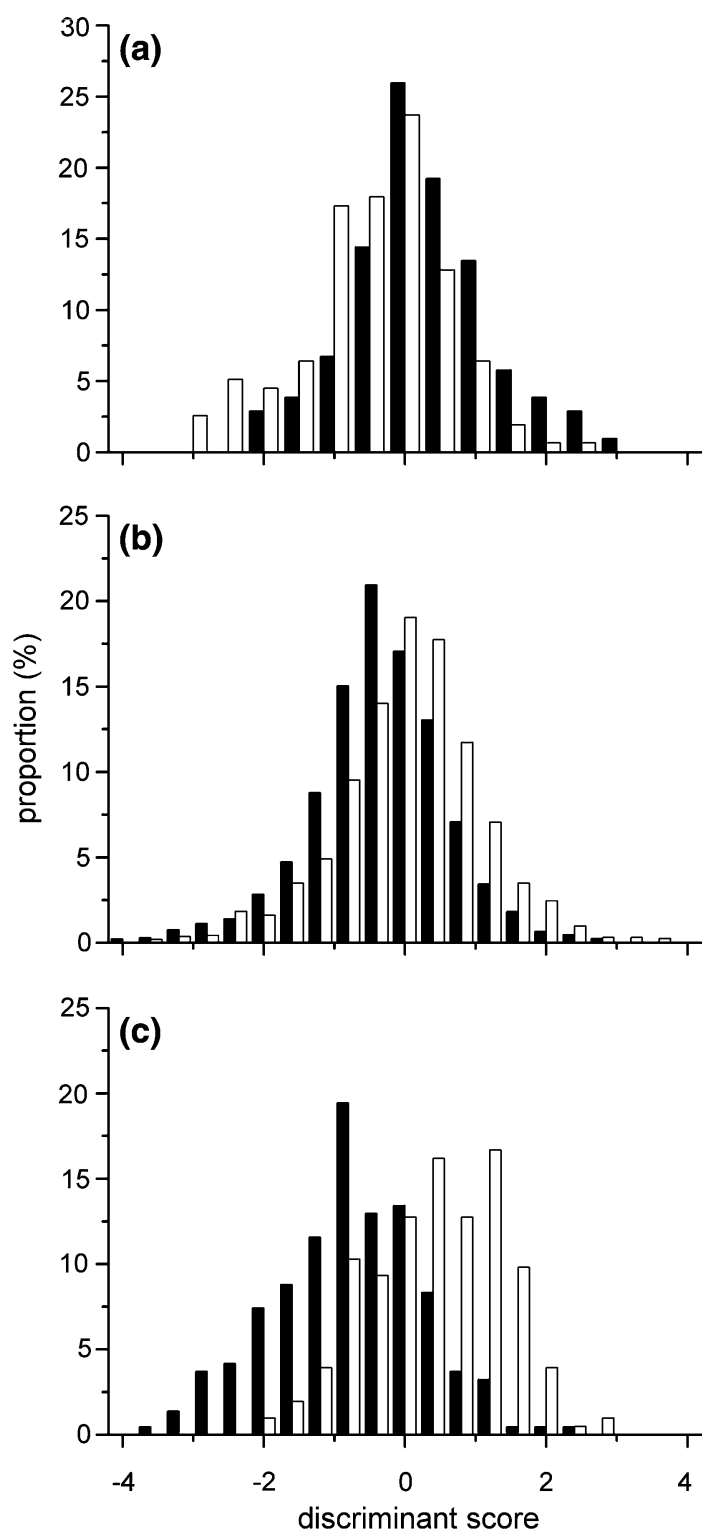

Fig. 1a-c Distributions of the first discriminant scores derived from a stepwise discriminant analysis used to differentiate the sexes of brown skuas (filled bars refer to males, open bars refer to females). Frequency distributions are shown for long calls (a), alarm calls (b) and contact calls (c). Discriminant scores are based on measurements of peak performance, note duration, peak amplitude and peak frequency for long calls (a), mean frequency, distance to maximum amplitude, peak frequency, frequency bandwidth, peak amplitude and maximum frequency for alarm calls (b), and peak amplitude, minimum frequency and note duration for contact calls (c)

general, males of monogamous birds often show secondary sexual traits that are considerably less extreme than those of polygamous species (Kirkpatrick et al. 1990). Therefore, one would not expect to find strong sex differences in the monogamous skuas. However, the findings of the present study are surprising, since no known morphological sexual dimorphism (e.g. body size or plumage ornamentation) is strong enough to enable skuas to identify the appropriate sex unambiguously. Although females exceed males in body size by $12 \%$ (Hahn et al. 2003), and white wing patches of females are larger than those of males (Hahn and Peter 2003), both traits overlap widely, making it very unlikely that they are used for sex recognition. With regard to sexual size dimorphism in brown skuas, it is remarkable that sexes do not even differ acoustically, even in the frequency domain. Usually, the sound frequency of the sender is negatively correlated with body size (Ryan and Brenowitz 1985). Therefore, one would expect that frequency measurements have higher values in males. Our results indicate that males tend to call at a higher frequency than females in all call types, but that sexes do not differ statistically. Interestingly, the most distinct acoustic parameter within the long call was peak performance. In brown skuas, this parameter reflects the individual quality in terms of mean reproductive success (Janicke et al. 2007), suggesting that it is a sexually selected acoustic trait. Nevertheless, our hypothesis that long calls provide an appropriate call type for sex differentiation must be rejected.

In conclusion, this study demonstrates that vocalisations of brown skuas are unlikely to be involved in the sex recognition process of that species, even though experimental evidence is still lacking. The mechanism of how brown skuas in particular and skuas in general identify the opposite sex, an essential task for pair formation, remains unresolved.

\section{Zusammenfassung}

Geschlechtererkennung bei Braunen Skuas: spielen akustische Signale eine Rolle?

Akustische Signale spielen bei vielen Vogelarten eine wesentliche Rolle bei der Geschlechtererkennung. Dies trifft insbesondere für Arten mit einem geringen morphologischen Sexualdimorphismus zu. Männchen und Weibchen der Braunen Skua Catharacta antarctica lonnberg, unterscheiden sich nur geringfügig hinsichtlich Gefiederfärbung und Morphologie, so dass Lautäusserungen potentiell eine grosse Bedeutung für die Geschlechtererkennung haben sollten. Wir untersuchten 8 bis 10 akustische Parameter von 3 Ruftypen (,,long call”, ,alarm call” und ,,contact call”) von 42 Individuen (20 Männchen, 22 Weibchen), deren Geschlecht mittels eines molekularen Markers bestimmt wurde. In keinem der 3 Ruftypen waren Unterschiede zwischen den Geschlechtern festzustellen. Zudem zeigte eine Diskriminanzanalyse, dass Männchen und Weibchen nicht zweifelsfrei zugeordnet werden können. Während für den ,contact call” $73 \%$ der Individuen 
ihrem Geschlecht richtig zugeordnet werden konnten, sank die Rate auf $64 \%$ für den ,,long call” und auf $60 \%$ für den ,alarm call" (bei einer zufällig richtigen Zuordnung von $50 \%$ ). Es ist demnach unwahrscheinlich, dass akustische Signale für die Geschlechtererkennung bei der Braunen Skua eine wesentliche Rolle spielen.

Acknowledgments Two anonymous referees made useful suggestions that improved the manuscript. This study was partially supported by the German Research Council (DFG, PE 454/1ff.). All field work was done in accordance with permissions issued by the Federal Environment Agency of Germany.

\section{References}

Ballintijn MR, ten Cate C (1997) Sex differences in the vocalizations and syrinx of the collared dove (Streptopelia decaocto). Auk 114:22-39

Bourgeois K, Curé C, Legrand J, Gómez-Díaz E, Vidal E, Aubin T, Mathevon N (2007) Morphological versus acoustic analysis: what is the most efficient method for sexing Yelkouan shearwaters Puffinus yelkouan? J Ornithol 148:261-269

Bradbury J, Vehrencamp SL (1998) Principles of animal communication. Sinauer, New York

Charrier I, Jouventin P, Mathevon N, Aubin T (2001) Individual identity depends on call type in the south polar skua Catharacta maccormicki. Polar Biol 24:378-383

Dunn PO, Whittingham LA, Pitcher TE (2001) Mating systems, sperm competition, and the evolution of sexual dimorphism in birds. Evolution 55:161-175

Fridolfsson A-K, Ellegren H (1999) A simple and universal method for molecular sexing of non-ratite birds. J Avian Biol 30:116121

Furness RW (1996) Family Stercorariidae (skuas). In: del Hoyo J, Elliott A, Sargatal J (eds) Handbook of the birds of the world, vol 3. Lynx Edicions, Barcelona, pp 556-571
Hahn S, Peter H-U (2003) Sex and age dependency of wing patch size in brown skuas. Emu 103:37-41

Hahn S, Ritz M, Peter H-U (2003) Living in mixed pairs-better for fitness? A study on skuas. In: Huiskes AHL, Gieskes WWC, Rozema J, Schorno RML, van der Vies SM, Wolff WJ (eds) Antarctic biology in a global context. Backhuys, Leiden, pp 229233

James PC (1984) Sexual dimorphism in the voice of the British Storm Petrel Hydrobates pelagicus. Ibis 126:89-92

Janicke T, Hahn S, Ritz M, Peter H-U (2007) Vocal performance reflects individual quality in a non-passerine. Anim Behav (in press)

Kirkpatrick M, Price T, Arnold SJ (1990) The Darwin-Fisher theory of sexual selection in monogamous birds. Evolution 44:180-193

Massey BW (1976) Vocal differences between American least terns and European little tern. Auk 93:760-773

Nuechterlein GL, Buitron D (1992) Vocal advertising and sex recognition in eared crebes. Condor 94:937-943

Olsen KM, Larsson H (1997) Skuas and jaegers: a guide to the skuas and jaegers of the world. Pica, Mountfield, UK

Owens IPF, Hartley IR (1998) Sexual dimorphism in birds: why are there so many different forms of dimorphism? Proc R Soc B 265:397-407

Phillips RA, Dawson DA, Ross DJ (2002) Mating patterns and reversed size dimorphism in southern skuas (Stercorarius skua lonnbergi). Auk 119:858-863

Pietz PJ (1985) Long call displays of sympatric south polar and brown skuas. Condor 87:316-326

Ryan MJ, Brenowitz EA (1985) The role of body size, phylogeny, and ambient noise in the evolution of bird song. Am Nat 126:87-100

Suthers RA (2004) How birds sing and why it matters. In: Marler P, Slabbekoorn H (eds) Nature's music: the science of bird song. Academic, New York, pp 272-295

Taoka M, Okumura H (1990) Sexual differences in flight calls and the cue for vocal sex recognition of swinhoe's storm-petrels. Condor 92:571-575

Taoka M, Sato T, Kamada T, Okumura H (1989) Sexual dimorphism of chatter-calls and vocal sex recognition in leach's storm-petrels (Oceanodroma leucorhoa). Auk 106:498-501 